\section{A New Route to (+)-Estrone Using a Bicyclo[3.2.1]octane Chiral Building Block}

\author{
Keisuke Hanada, Norio Miyazawa, and \\ Kunio Ogasawara*
}

Pharmaceutical Institute, Tohoku University; Aobayama, Sendai 980-8578, Japan.

Received November 5, 2002; accepted December 3, 2002

A new route to (+)-estrone has been developed starting from the chiral building block having a bicyclo[3.2.1]octane framework based on the inherent stereochemical chemical nature of the chiral building block.

Key words chiral building block; diastereo-controlled synthesis; aldol reaction; Dieckmann condensation; steroid

We have recently developed an efficient preparation of the chiral building block 2 by a route involving either an enzymatic $^{1)}$ or a chemical ${ }^{2)}$ resolution step. Because of its inherent stereochemical and chemical nature with a sterically biased structure, it serves as a versatile chiral building block and has already been used in the efficient stereocontrolled syntheses of the antibiotic diterpene (+)-ferruginol, ${ }^{1)}$ the calcitriol A-ring ${ }^{3)}$ and $\mathrm{C} / \mathrm{D}$-ring ${ }^{2)}$ precursors, the analgesic alkaloid (-)-morphine ${ }^{4}$ and the structurally related morphinan alkaloid (-)-O-methylpallidinine, ${ }^{5)}$ the antitumor sesquiterpene (+)-vernolepin, ${ }^{6}$ and the 18 -yohimbones. ${ }^{7)}$ We have now attempted its conversion into the representative estrogenic steroid hormone (+)-estrone $\mathbf{1}^{8-15)}$ applying the same synthetic methodology employed in the syntheses of the above mentioned natural products. We report here a new route leading to $(+)$-estrone 1 starting with the building block (-)-2 by employing the regioselective retro-Dieckmann reaction and the ring-closing metathesis ${ }^{16-19)}$ as key steps (Fig. 1).

Because of its sterically biased structure, the bicyclic enone (-)-2 exhibited convex-face selectivity to allow diastereoselective introduction of the vinyl functionality at the $\beta$-position to give the single ketone $3,[\alpha]_{\mathrm{D}}^{24}-101.9^{\circ}(c=1.5$, $\mathrm{CHCl}_{3}$ ). Reduction of $\mathbf{3}$ with sodium borohydride afforded

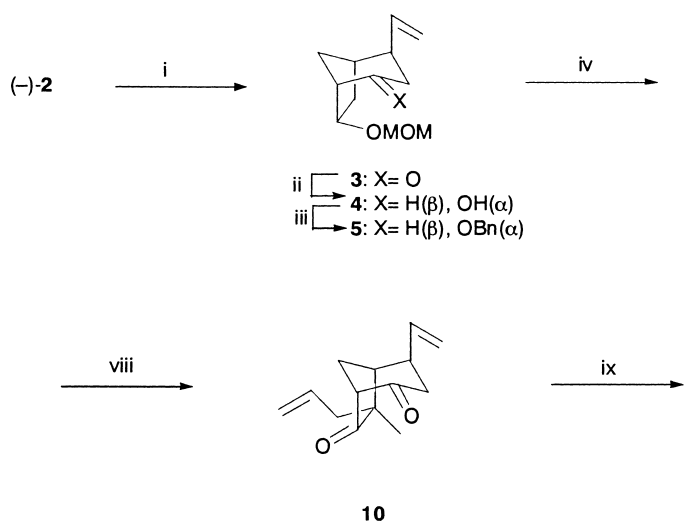

the secondary alcohol $4,[\alpha]_{\mathrm{D}}^{23}-73.2^{\circ}\left(c=1.3, \mathrm{CHCl}_{3}\right)$, diastereoselectively which was transformed into the benzyl ether $5,[\alpha]_{\mathrm{D}}^{25}+20.7^{\circ}\left(c=1.3, \mathrm{CHCl}_{3}\right)$, under standard conditions. On sequential removal of the MOM-protecting group and oxidation, the ether 5 gave the ketone $7,[\alpha]_{\mathrm{D}}^{24}-135.8^{\circ}$ $\left(c=1.6, \mathrm{CHCl}_{3}\right)$, via the secondary alcohol $\mathbf{6},[\alpha]_{\mathrm{D}}^{24}-29.4^{\circ}$ $\left(c=1.5, \mathrm{CHCl}_{3}\right)$. Owing to its molecular bias, the ketone 7 allowed diastereoselective installation of the quaternary stereogenic center to give the single dialkylated ketone $\mathbf{8},[\alpha]_{D}^{24}$ $-63.6^{\circ}\left(c=1.4, \mathrm{CHCl}_{3}\right)$, by sequential methylation and allylation under basic conditions. After debenzylation with 2,3dichloro-5,6-dicyanobenzoquinone (DDQ), ${ }^{6,20)}$ the resulting keto-alcohol 9, $[\alpha]_{\mathrm{D}}^{23}+38.7^{\circ}\left(c=1.4, \mathrm{CHCl}_{3}\right)$, was oxidized to the $\beta$-diketone 10, $[\alpha]_{\mathrm{D}}^{24}-228.4^{\circ}\left(c=1.4, \mathrm{CHCl}_{3}\right)$, with pyridinium chlorochromate (PCC). As observed in the previously reported synthesis of the C/D-ring moiety of calcitriol, ${ }^{2,3)}$ and $(+)$-vernolepine, ${ }^{6)}$ exposure of the diketone $\mathbf{1 0}$ to sodium methoxide in methanol induced a facile regioselective retro-Dieckmann reaction to afford the single cyclopentanone 12, $[\alpha]_{\mathrm{D}}^{24}+96.6^{\circ}\left(c=1.3, \mathrm{CHCl}_{3}\right)$, in excellent yield. The observed regioselective cleavage may be due to the steric environment of the two carbonyl functionalities in which the less congested cyclohexanone carbonyl was preferentially attacked by methoxide ion to generate a transient $\beta$ keto-alkoxide intermediate $\mathbf{1 1}$ to lead exclusively to the cyclopentanone 12 destined for the BCD-ring moiety of (+)estrone 1 (Fig. 2).

In order to construct the C-ring moiety of (+)-estrone $\mathbf{1}$, the cyclopentanone $\mathbf{1 2}$ was refluxed with the Grubbs' reagent in dichloromethane to initiate the ring-closing metathesis. The expected reaction took place readily to give the hydroindanone 13, $[\alpha]_{\mathrm{D}}^{23}+90.4^{\circ}\left(c=1.4, \mathrm{CHCl}_{3}\right)$, the C/D-ring moiety of $(+)$-estrone 1 , in excellent yield. The bicyclic ketone

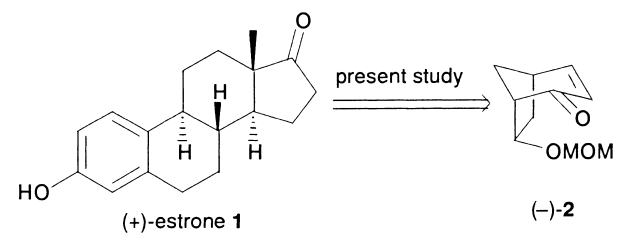

Fig. 1
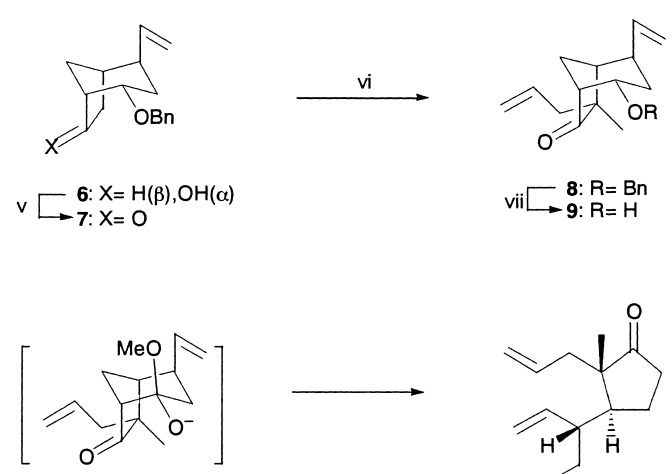

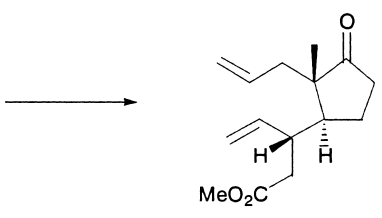

12

Fig. 2.

Reagents and conditions: i) vinylmagnesium bromide, $\mathrm{CuBr}-\mathrm{Me}_{2} \mathrm{~S}$, TMSCl, HMPA, THF, $-78{ }^{\circ} \mathrm{C}$ then TBAF (93\%). ii) $\mathrm{NaBH}_{4}, \mathrm{MeOH},-78--30{ }^{\circ} \mathrm{C}(92 \%)$, iii) $\mathrm{BnBr}$, $\mathrm{NaH}$, $\mathrm{Bu}_{4} \mathrm{NI}$, THF, reflux (80\%), iv) $\mathrm{HCl}-\mathrm{MeOH}(94 \%)$. v) $\mathrm{PCC}, \mathrm{CH}_{2} \mathrm{Cl}_{2}(94 \%)$. vi) MeI, $\mathrm{NaH}$, THF, then allyl bromide, $\mathrm{Bu}^{t} \mathrm{OK}, \mathrm{THF}$ ( $77 \%, 2$ steps). vii) $\mathrm{DDQ}, \mathrm{H}_{2} \mathrm{O}, \mathrm{CH}_{2} \mathrm{Cl}_{2}(77 \%)$. viii) $\mathrm{PCC}, \mathrm{CH}_{2} \mathrm{Cl}_{2}$ (94\%). ix) $\mathrm{NaOMe}, \mathrm{MeOH}(93 \%)$. 

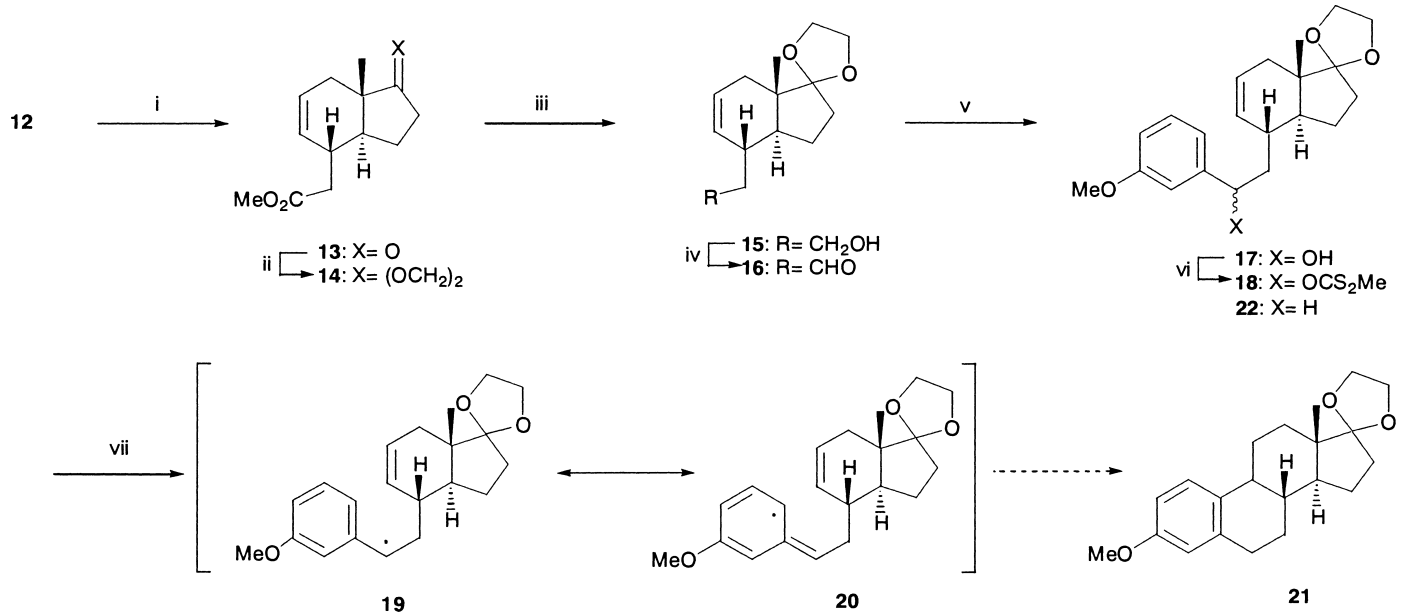

Fig. 3 .

Reagents and conditions: i) Grubbs' catalyst (5 mol\%), $\mathrm{CH}_{2} \mathrm{Cl}_{2}$, reflux (90\%). ii) $\left(\mathrm{TMS}-\mathrm{OCH}_{2}\right)_{2}$, TMS-OTf, $\mathrm{CH}_{2} \mathrm{Cl}_{2},-78-0{ }^{\circ} \mathrm{C}(93 \%)$. iii) $\mathrm{LiAlH} 4$, THF $(98 \%)$. iv) $\mathrm{PCC}$, $\mathrm{CH}_{2} \mathrm{Cl}_{2}$. v) 3-MeOC $\mathrm{H}_{4} \mathrm{MgBr}$, THF, $-78^{\circ} \mathrm{C}$ (71\%, 2 steps). vi) $\mathrm{CS}_{2}$, MeI, NaH, THF (93\%). vii) $\mathrm{Bu}{ }_{3} \mathrm{SnH}$, AIBN, toluene, reflux ( $86 \%$ for 22 ).
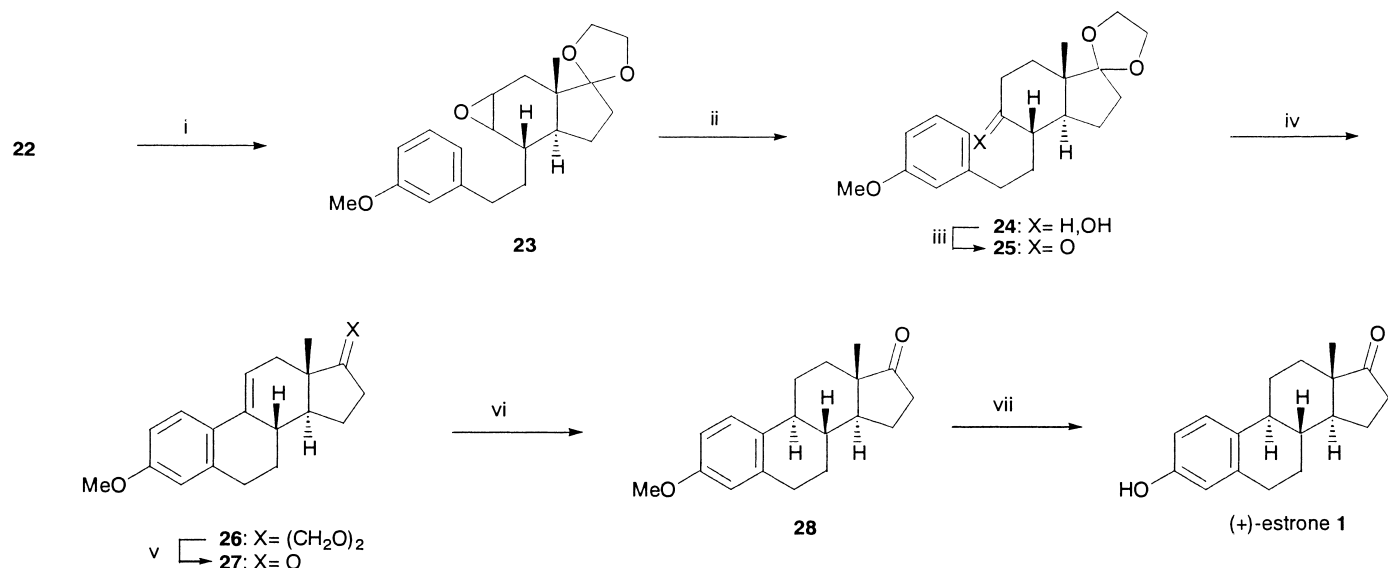

(+)-estrone 1

Fig. 4 .

Reagents and conditions: i) $m$ - $\mathrm{CPBA}, \mathrm{NaHCO}_{3}, \mathrm{CH}_{2} \mathrm{Cl}_{2}(98 \%)$. ii) DIBAL, $\mathrm{CH}_{2} \mathrm{Cl}_{2},-78^{\circ} \mathrm{C}(64 \%)$. iii) $\mathrm{PCC}, \mathrm{CH}_{2} \mathrm{Cl}_{2}(84 \%)$. iv) $\left(\mathrm{CH}_{2} \mathrm{OH}\right)_{2}, p$ - $\mathrm{TsOH}$ (cat.), toluene, reflux. v) $p$ $\mathrm{TsOH}$, aq. acetone, reflux (88\%, 2 steps). vi) $\mathrm{Et}_{3} \mathrm{SiH}, \mathrm{CF}_{3} \mathrm{CO}_{2} \mathrm{H}$, benzene (82\%). viii) $\mathrm{BBr}_{3}, \mathrm{CH}_{2} \mathrm{Cl}_{2},-30-0^{\circ} \mathrm{C}(84 \%)$.

13 obtained was ketalized and the resulting ethylene ketal 14, $[\alpha]_{\mathrm{D}}^{23}-64.6^{\circ}\left(c=1.4, \mathrm{CHCl}_{3}\right)$, was transformed into the aldehyde 16 via the primary alcohol 15, $[\alpha]_{\mathrm{D}}^{24}-65.7^{\circ}(c=1.5$, $\mathrm{CHCl}_{3}$ ), by sequential reduction with lithium aluminum hydride and oxidation with PCC gave the benzyl alcohol $\mathbf{1 7}$ as an epimeric mixture which without separation was transformed into the xanthate 18. Our first intention was a reductive cyclization of the xanthate $\mathbf{1 8}$ to give rise to the tetracyclic steroid framework 21 via mesomeric radical intermediates such as $\mathbf{1 9}$ and $\mathbf{2 0}$. However, the product obtained was not the expected tetracyle $\mathbf{2 1}$ but the simple reduction product 22, $[\alpha]_{\mathrm{D}}^{25}-82.1^{\circ}\left(c=1.2, \mathrm{CHCl}_{3}\right)$, when the xanthate 18 was treated with tributylstannane in toluene at reflux in the presence of azobisisobutylonitrile (AIBN) (Fig. 3).

We, therefore, explored an alternative route to $(+)$-estrone $\mathbf{1}$ using the reduction product 22. Thus, the product $\mathbf{2 2}$ was transformed into the epoxide 23, $[\alpha]_{\mathrm{D}}^{23}-63.1^{\circ} \quad(c=1.2$, $\left.\mathrm{CHCl}_{3}\right)$, on reaction with $m$-chloroperbenzoic acid $(m$ CPBA) which generated a single diastereomer. Since direct transformation of the epoxide $\mathbf{2 3}$ into the ketone $\mathbf{2 5}$ under acid-catalyzed conditions failed, it was treated with diisobutylaluminum hydride (DIBAL) at $-78^{\circ} \mathrm{C}$ to give the single secondary alcohol 24, $[\alpha]_{\mathrm{D}}^{24}-35.4^{\circ}\left(c=1.3, \mathrm{CHCl}_{3}\right)$, which, obtained regioselectively, was then oxidized with PCC to give the ketone 25, $[\alpha]_{\mathrm{D}}^{24}-7.1^{\circ}\left(c=1.3, \mathrm{CHCl}_{3}\right)$. When the ketone $\mathbf{2 5}$ was refluxed with ethylene glycol in toluene in the presence of $p$-toluenesulfonic acid, a facile cyclization occurred, as we have so far observed in certain cases, ${ }^{1,4,5,7)}$ to give the tetracyclic product $\mathbf{2 6}$ as a mixture of two regio-isomers. After acid-catalyzed deketalization of the mixture 26, the resulting keto-olefin mixture 27, consisting of the $\Delta^{9,11}$-isomer and the $\Delta^{8,9}$-isomer in a $7: 3$ ratio estimated by ${ }^{1} \mathrm{H}-\mathrm{NMR}$ analysis, was treated with triethylsilane in benzene containing trifluoroacetic acid $^{10-12,21)}$ to give $(+)$ estrone methyl ether $28, \mathrm{mp} .174-175^{\circ} \mathrm{C},[\alpha]_{\mathrm{D}}^{27}+152.6^{\circ}$ $\left(c=1.2, \mathrm{CHCl}_{3}\right)\left[\right.$ lit. $^{10)}: \mathrm{mp} 174-175.5^{\circ} \mathrm{C},[\alpha]_{\mathrm{D}}^{27}+159.2^{\circ}$ $\left.\left(c=0.72, \mathrm{CHCl}_{3}\right)\right]$, as a single product which was identical in all respects with an authentic material. Since the methyl ether 28 has been transformed into $(+)$-estrone $\mathbf{1}$ in a single step, ${ }^{8-15)}$ a new route has been established at this stage in a formal sense. Actually, the ether $\mathbf{2 8}$ furnished $(+)$-estrone 1, $\operatorname{mp} 265-266^{\circ} \mathrm{C},[\alpha]_{\mathrm{D}}^{26}+151.8^{\circ}\left(c=0.5, \mathrm{CHCl}_{3}\right)\left[\right.$ lit. $^{10)}: \mathrm{mp}$ $\left.265.0-266.5^{\circ} \mathrm{C},[\alpha]_{\mathrm{D}}^{27}+152.2^{\circ}\left(c=0.31, \mathrm{CHCl}_{3}\right)\right]$, on exposure to boron tribromide in dichloromethane (Fig. 4). 
In summary, we have developed a new route to $(+)$-estrone 1 starting with our bicyclo[3.2.1] octane building block $(-)-2$ and have extended the versatility of our chiral building block.

Acknowledgements We are grateful to the Ministry of Education, Culture, Sports, Science and Technology, Japan, for support of this research and to Professor Yoshiharu Iwabuchi, Pharmaceutical Institute, Tohoku University, for his kind suggestions.

\section{References and Notes}

1) Nagata H., Miyazawa N., Ogasawara K., Org. Lett., 3, 1737-1740 (2001).

2) Hanada K., Miyazawa N., Nagata H., Ogasawara K., Synlett, 2002, $125-127$ (2002).

3) Miyazawa N., Tosaka A., Hanada K., Ogasawara K., Heterocycles, in press.

4) Nagata H., Miyazawa N., Ogasawara K., Chem. Commun., 2001, $1094-1095$ (2001).

5) Hanada K., Miyazawa N., Ogasawara K., Org. Lett., in press (ASAP ol027040n).

6) Miyazawa N., Nagata H., Ogasawara K., Synlett, 2002, 1065-1068 (2002).

7) Miyazawa N., Ogasawara K., Tetrahedron Lett., 43, 4773-4776 (2002).

8) For some recent examples, see: Quinkert G., Grosso M. D., Bucher A., Bats J. W., Dürner G., Tetrahedron Lett., 32, 3357-3360 (1991).
9) For some recent examples, see: Quinkert G., Grosso M. D., Bucher A., Bauch M., Döring W., Bats J. W., Dürner G., Tetrahedron Lett., 33, $3617-3620$ (1992).

10) For some recent examples, see: Takano S., Moriya M., Ogasawara K., Tetrahedron Lett., 33, 1909-1910 (1992).

11) For some recent examples, see: Quinkert G., Grosso M. D., Döring A., Döring W., Schenkel R. I., Bauch M., Dambacher F. T., Bats J. W., Zimmermann G., Dürner G.. Helv. Chim. Acta, 78, 1345-1391 (1995).

12) For some recent examples, see: Sugahara T., Ogasawara K., Tetrahedron Lett., 37, 7403-7406 (1996).

13) For some recent examples, see: Tietze L. F., Nöbel T., Spesch M., J. Am. Chem. Soc., 120, 8971-8977 (1998).

14) For some recent examples, see: Rigby J. H., Warshakoon N. C., Payen A. J., J. Am. Chem. Soc., 121, 8237-8245 (1999).

15) For some recent examples, see: Tanaka K., Nakashima H., Taniguchi T., Ogasawara K., Org. Lett., 2, 1915-1917 (2000).

16) For pertinent reviews, see: Grubbs R. H., Chang S., Tetrahedron, 54, 4413-4450 (1998).

17) For pertinent reviews, see: Roy R., Das S. K., Chem. Commun., 2000, 519-529 (2000).

18) For pertinent reviews, see: Fürstner A., Angew. Chem. Int. Ed., 39, 3012-3043 (2000).

19) For pertinent reviews, see: Trnka T. M., Grubbs R. H., Acc. Chem. Res., 34, 18-29 (2002).

20) Matsumura R., Suzuki T., Hagiwara H., Hashi T., Ando M., Tetrahedron Lett., 42, 1543-1546 (2001).

21) Posner G. H., Switzer C., J. Am. Chem. Soc., 108, 1239-1244 (1986). 